\title{
Molecular characterization of the porcine hyaluronidase gene cluster on SSC13q21
}

\author{
Dissertation \\ zur Erlangung des Doktorgrades \\ der Fakultät für Agrarwissenschaften \\ der Georg-August-Universität Göttingen
}

\author{
vorgelegt von \\ Kesinee Gatphayak \\ geboren in Chiangmai/Thailand
}

Göttingen, Dezember 2003 
D7

1. Referent: Prof. Dr. Dr. Bertram Brenig

2. Korreferent: Prof. Dr. Udo ter Meulen

Tag der Mündlichen Prüfung: 5.2.2004 
To my family... 
TABLE OF CONTENTS

1 LIST OF PUBLICATIONS ........................................................................... 2

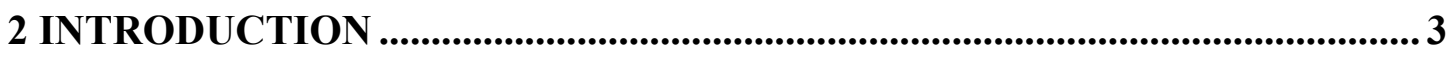

3 HYALURONAN AND HYALURONIDASES................................................. 4

3.1 Structure, physiology and function of hyaluronic acid (hyaluronan) .................. 4

3.2 Structure, physiology and function of hyaluronidases ..................................... 5

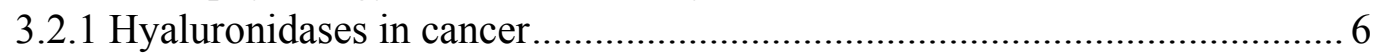

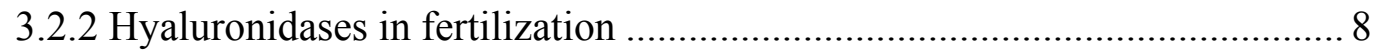

3.2.3 Hyaluronidases in Descensus testis ...................................................... 9

3.3 MOLECULAR ANALYSIS OF HYALURONIDASE GENES ..................... 14

3.3.1 HYAL GENES .............................................................................. 14

3.3.2 Genes of the human hyaluronidase gene cluster on chromosome $3 q 21.3 . .16$

3.4 Genes of the hyaluronidase gene cluster in pigs........................................... 25

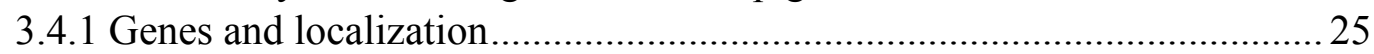

3.4.2 Associations between hyaluronidases and pigs ..................................... 26

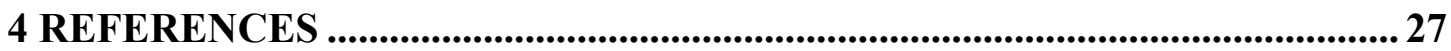

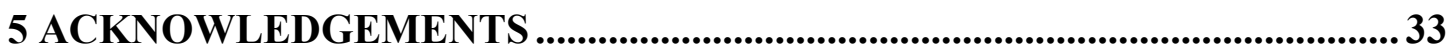

CURRICULUM VITAE .............................................................................................34 


\section{LIST OF PUBLICATIONS}

This thesis is based on the following papers:

\section{A. Peer-reviewed journals:}

Gatphayak K., Knorr C., Habermann F., Fries R. and Brenig B. (2003): Assignment of the porcine hyaluronidase-3 (HYAL3) gene to SSC13q21 by FISH and confirmation by hybrid panel analyses. Cytogenet. Genome Res 101, 178F

Gatphayak K., Knorr C. and Brenig B. (2003): Assignment of the porcine FUS1 gene to SSC13q21-q22 by somatic cell and radiation hybrid panel mapping. Cytogenet Genome Res 103 (in press, DOI:10.1159/000076322)

Gatphayak K., Knorr C., Chen K.F. and Brenig B. (2004): Structural and expression analysis of the porcine FUS2 gene. (accepted for publication in Gene; January 22, 2004)

Gatphayak K., Knorr C. and Brenig B. (2004): Molecular characterization of porcine hyaluronidase genes 1, 2, and 3 clustered on SSC13q21. (accepted for publication in Cytogenet Genome Res; January 21, 2004)

Chen K.F., Knorr C., Moser G., Gatphayak K. and Brenig B. (2004): Molecular characterization of the porcine testis-specific phosphoglycerate kinase 2 (PGK2) gene and its association with male fertility. (revised version in preparation)

\section{B. Congress contribution:}

Gatphayak K., Knorr C. and Brenig B. (2003): Molecular characterization of the porcine hyaluronidase genes cluster on SSC13q21. DGfZ/GfT-Convention, Goettingen 17./18. September 2003, B12 


\section{INTRODUCTION}

Molecular genetics is now providing tools to enhance rates of genetic improvement by selection on quantitative trait loci (QTL) or on linked markers. Therefore, molecular genetics enables to identify genes affecting quantitative traits. The new knowledge applied in pig genomics coupled with global methods of detecting genetic abnormalities will provide implications for clinical medicine.

The aim to study hyaluronidase genes $(H Y A L)$ is lying in their ability to be candidate genes for cancer, fertilization mechanisms, as well as their role in hyaluronan degradation particularly in the Descensus testis process. Two groups of three genes each were identified on human chromosomes $3 p 21.3$ and $7 q 31.3$. The genes on chromosome 3 are more closely related to each other and have a similar genomic structure in terms of intron and exon arrangement than the two genes and the pseudogene on chromosome 7 that are not preserved. The porcine HYAL genes on chromosome 3 HYAL1, HYAL2 and HYAL3 were chosen in the beginning of our studies and later FUS1 and FUS2 were also included. Although the background of these genes are identified based on being tumor suppressor gene (TSG) candidates, (homozygous deletions of the genes of the $3 p 21.3$ region result in tumor suppressor activities), their individual contributions to overall hyaluronan degradation is well documented.

The following molecular genetic studies of the porcine $H Y A L$ genes report the genes' structure, their chromosomal assignment, their expression patterns and existing polymorphisms. Knowledge of the molecular structure leads to suggest a role for hyaluronidases in biological processes which may be implemented in further studies to use hyaluronidases as a diagnostic marker and the pig as a model animal in cancer research and therapy. 


\section{HYALURONAN AND HYALURONIDASES}

\subsection{Structure, physiology and function of hyaluronic acid (hyaluronan)}

Hyaluronan or hyaluronic acid (HA) is a member of the family of complex carbohydrates known as glycosaminoglycans (GAGs). It is found in the extracellular matrix especially of soft connective tissues. The chemical structure consists of repeated disaccharide units of $\mathrm{N}$-acetyl-D-glucosamine and D-glucuronic acid linked by $\beta(1-4)$ and $\beta(1-3)$ glycosidic bonds (figure 1). Hyaluronan is a large polymer with an average range of approximately 25,000 disaccharide units. Hyaluronan molecules can be stabilized and thereby form a stiffened helical configuration. Water can be trapped within this stiffened conformation (Jacobson, 2002). When the amount of HA in a solution reaches a concentration of approximately $0.1 \mathrm{mg} / \mathrm{ml}$, the molecule forms an entangled network. Inter- and intramolecular interactions occur such that the volume occupied by HA increases, resulting in the exclusion of other macromolecules from their normal molecular environment. This is called steric exclusion that can influence both osmotic activity and transport in the extracellular matrix since water is immobilized and flow-restricted. The overall turnover rate $\left(t_{1 / 2}\right)$ is rapid for a connective tissue matrix component with $\left(t_{1 / 2}=0.5\right.$ to a few day) (Laurent and Fraser, 1992). HA is synthesized by HA synthase (HAS) in the plasma membrane and extrudes then into the extracellular space. The synthesis is regulated by various factors in mammals like growth factors, hormones and inflammatory mediators (Jacobson, 2002).

The molecular functions of HA are considered to fall into three partially overlapping categories: First, because of its unique hydrodynamic properties, HA occupies an enormous hydrodynamic domain that influences the hydration and physical properties of the tissues. Second, by its instructive effects on cell signaling and behavior, it interacts with other extracellular matrix macromolecules and hyaluronan-binding macromolecules (hyaladherins) such as versican and aggrecan (Knudson, 1996; Toole, 2001). Finally, HA interacts with cell surface receptors, notably CD44 and RHAMM (receptor for hyaluronanmediated motility) transducing intracellular signals to regulate cell growth, survival and movement (Turley et al., 2002).

Hyaluronan has also been recognized in clinical medicine as serum hyaluronan is a promising reagent in the diagnosis of liver diseases and various inflammatory conditions (Laurent and Fraser, 1992). 


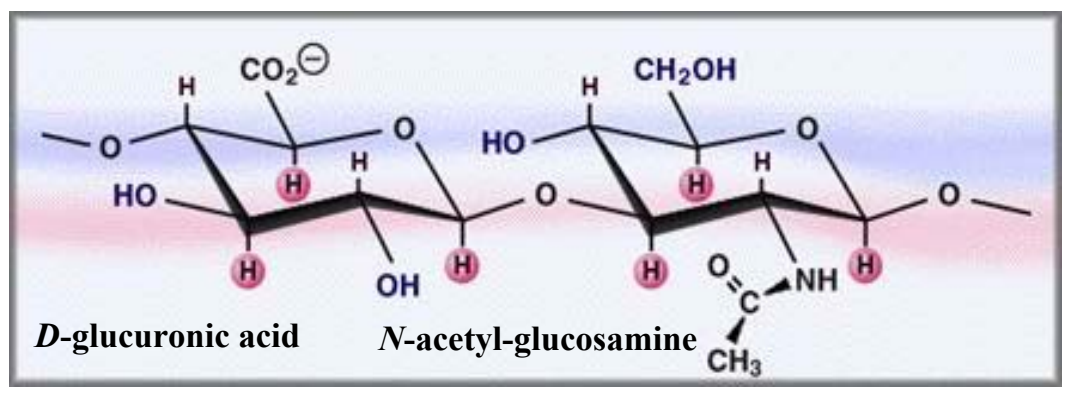

Figure 1: Structure of hyaluronic acid. Hydrogen atoms form a non-polar, relatively hydrophobic face while the equatorial side chains form a more polar, hydrophilic face, thereby creating a twisting ribbon structure (adapted from Laurent and Hascall, 1997).

\subsection{Structure, physiology and function of hyaluronidases}

In vertebrate tissues, degradation of hyaluronan occurs by the concerted action of three enzymes: a hyaluronidase and two exoglycosidases that remove sugars sequentially from the non-reducing termini, a beta-glucuronidase and a beta-N-acetyl-glucosaminidase. Hyaluronidases (HAases) are enzymes responsible for most of the degradation of HA as they catalyze the random hydrolysis of 1,4-linkages between $\mathrm{N}$-acetyl- $\beta$-D-glucosamine and D-glucuronate residues in hyaluronan (Kreil, 1995). The endolytic cleavage by the hyaluronidase generates increasing numbers of non-reducing termini for the exoglycosidases. The relative contribution of the endo- and exocleavage reactions varies from tissue to tissue. Though these enzymes have the same or similar substrates, their mechanisms vary in a wide range of $\mathrm{pH}$ optima according to substrate specificity or by their reaction product. Hyaluronidases are members of a class of endoglycosamine enzymes of considerable complexity and heterogeneity.

Three principal types of hyaluronidases have been characterized, mammalian (EC 3.2.1.35), bacterial (EC 4.2.99.1) and hyaluronidases from leeches, other parasites and crustaceans (EC 3.2.1.36) and are grouped as endo-beta-N-acetyl hexosaminidases (mammalian and bacterial) or endo-beta-glucuronidases (leeches, other parasites, and crustaceans) with different end products (Stern and Csoka, 2000). The first eukaryotic hyaluronidase which could be cloned was from the bee venom which is homologous to the PH-20 hyaluronidase found in human spermatozoa (Kreil, 1995; Gmachl and Kreil, 1993).

The testis specific hyaluronidase has long been recognized and characterized. The commercially used hyaluronidase was isolated from sheep and bovine testes, since hyaluronidase plays a vital role in fertilization of the mammalian egg (Baba et al., 2002). 
Recently, HAase extracted from Norway lobster (Nephrops norvegicus) was also successfully commercially used (Krishnapillai et al., 1999). The examples of applications of hyaluronidases in the pharmaceutical and food industry show that dispersion and absorption of other drug and treatment of cancer (Seravac, 2001) is facilitated considering them as putative virulent factors of pathogenic organisms in cultures (CIRVAL, 2003).

\subsubsection{Hyaluronidases in cancer}

Interactions between hyaluronan and cells in cancer progression are reviewed by Toole et al. (2002). Various tumors are surrounded by a connective tissue matrix (stroma) enriched with hyaluronan. The enzyme hyaluronidase appears to interfere with metastasis, the process by which tumors spread from the primary organ in which they arose to other sites in the body, through three mechanisms. Two of the requirements for cancer cells to metastasize are that they must become motile, and that they must have a space into which to move. Hyaluronan accomplishes both of these tasks. Hyaluronan on the surface of cancer cells hydrates, expands, and opens up spaces around cancer cells, enabling them to invade surrounding tissues. One suggestion is that invasive tumor cells, or products secreted by these cells, induce stimulation of hyaluronan synthesis by stromal cells such as fibroblasts or smooth muscle cells (Knudson and Knudson, 1995). An increase of hyaluronan may provide an embryonic-like environment that facilitates tumor cell migration (Knudson, 1996), as an enhanced of cell motility (migration) is necessary for cells to become metastatic (Zetter Research Lab, 2003). Using animal models, rabbit V2 carcinoma was studied by Toole et al. (1979) demonstrating that the accumulation of hyaluronan is correlated with tumor invasiveness.

Hyaluronan also allows tumor cells to protect themselves against immune assaults by such mechanisms as the secretion of non-specific suppressive or anti-inflammatory factors or the shedding of tumor-specific antigens such as lymphocyte-mediated cytolysis. Removal of hyaluronan present in the extracellular matrix of tumor cells by hyaluronidase renders the latter more accessible to effector T cells. Experiments showed in transplanted mice suffering two tumors (3LL lung carcinoma and the B16F10 melanoma) that tumor proliferation is influenced by hyaluronidase 1 (HYAL1). Both tumors developed more slowly, measured by a slower rate of increase in local tumor size and by a prolonged survival time, in presence of higher levels of circulating hyaluronidase concentrations (De Maeyer and De Maeyer-Guignard, 1992). Hyaluronidase treatment destroys the hyaluronate coat surrounding tumor cells and allows lymphocytes to approach the tumor 
membrane to enhance the cytotoxic action of immune response (McBride and Bard, 1979) and to be more accessible both for tumor-specific cytotoxic-T-cell generation and activity (De Maeyer and De Maeyer-Guignard, 1992).

The hydrodynamic effect of hyaluronan on the extracellular matrix interacts with cell migration, a role mediated via cell surface by hyaluronan-binding sites or hyaluronan receptors. Hyaluronidase breaks down $\mathrm{HA}$ and eliminates as a direct effect of this mechanism cancer cell spread. The receptor for HA, the lymphocyte homing receptor CD44, functions as an anchor to bind HA to the cancer cell surface. CD44 comes in a variety of forms, a short form found on normal cells, and longer variants that occur on motile cancer cells only (Knudson, 1996). A portion of CD44 protrudes through the surface membrane into the cell cytoplasm, where it interacts with the cytoskleleton, the machinery for cell movement. Interactions between hyaluronan and CD44 have been reported to play the critical role in the process of tumor metastasis. They promote the formation of tumor embolisms, which in turn, increase the chances that the tumor cells would be trapped in the lungs (Zhang et al., 1995). As shown experimentally, inserting this longer cancer form of CD44 into tumor cells changes them into cancer cells that aggressively metastasize. Hyaluronidase eliminates the cancer cells' ability to move, by converting the long cancer form of CD44 to the short "normal" immobile form. A molecular and cell biology study to determine precisely how hyaluronidase regulates this alternative splicing of CD44 is done in the California Breast cancer research project. Understanding of these events in the regulation of CD44 will finally make it possible to develop a new generation of anticancer drugs to prevent metastases associated with breast cancer progression.

Another receptor RHAMM (an inherant hyaldherin), functions primary in stimulating a locomotry, chemokinetic response of tumor cells to soluble hyaluronan. RHAMM does not appear to be directly related to CD44 or hyaluronan-binding proteoglycans (i.e. does not contain B-loop structure) but may share common structural motifs within the actual hyaluronan-binding domain (Knudson, 1996). The ability of intracellular RHAMM forms to associate with multiple signaling complexes and cytoskeleton suggest that they function as adapter proteins like vinculin and plaxillin. Hyaluronan-RHAMM interactions induce transient phosphorylation of focal adhesion kinase, $\mathrm{p} 125^{\mathrm{FAK}}$, leading to initiation of locomotion. Suppression of this interaction inhibits both cell locomotion and proliferation and leads to inhibition of tumor growth. Whereas, 
over-expression of RHAMM leads to enhanced tumor growth and metastasis (Toole et al., 2002).

The third function of hyaluronidase was reviewed by Stern (1995). The enzyme causes established breast cancers to shrink. Inoculation of hyaluronidase in mice suffering human breast cancer shrinks the tumor to half its size in four days. The malignant cells cannot maintain motility and thus invasiveness, and the tumor cannot progress or grow and must completely apparently undergo regression. These biological mechanisms are still not understood, but may be a consequence of the two functions as mentioned before. Hyaluronidase may thus prevent progression of human breast cancer, and it seems not to have the devastating toxic side effects of other anticancer agents.

Another role of hyaluronidase in the context of cancer may be the inhibition of tumor cell growth by an increased tumor necrosis factor (TNF) cytotoxicity. HAase counteracts transforming growth factor beta mediated (TGF-beta-mediated) TNFresistance and suppresses TGF-betal gene expression. Hyaluronidase antagonizes TGFbeta-mediated inhibition of epithelial cell growth. Both TGF-beta and hyaluronidase are essential for the progression and invasiveness of breast, prostate and other cancers. A stage-dependent expression, as well as a balanced production of these proteins is essential for cancer development and self protection against TNF cytotoxicity (Chang, 1998). It has been shown that hyaluronidase is able to disrupt intercellular adhesion and to chemosensitize tumor cells by a mechanism, independent of increased drug penetration in cancer chemotherapy (Buschauer, 2003).

\subsubsection{Hyaluronidases in fertilization}

The process of fertilization begins when the sperm contacts the outermost egg investment (cumulus cells) and ends with fusion of two haploid pronuclei in the egg cytoplasm. Many steps in fertilization involve carbohydrate-based molecular recognition between sperm and egg. Vertebrate egg coats contain zona pellucida (ZP) family glycoproteins whose carbohydrates bind to sperm receptors. Fertilization is a multistep process: sperm must locate and fuse with the egg and the egg must prevent further sperm fusion to avoid pathological polyspermy. An extracellular matrix surrounds eggs. When sperm contacts this matrix, there are primary binding events that lead to the sperm acrosome reaction (AR). The AR is triggered by increases in intracellular $\mathrm{Ca}+$ and $\mathrm{pH}$ resulting in exocytosis of the acrosomal vesicle in the sperm head. Then the membrane exposed by AR fuses with the egg plasma membrane. Protein-carbohydrate interactions 
play a critical role in this complex process (Kathryn and Victor, 2001; Naz and Vanek, 1998).

The protein of the sperm hyaluronidase SPAM1 (sperm adhesion molecule), PH-20 aids in penetrating the layer of cumulus cells by digesting hyaluronic acid (Gmachl and Kreil, 1993). PH-20 is expressed in testis in two forms. During fertilization, one form is present on the surface of the acrosomal head of sperm which is tethered to the plasma membrane by the lipid anchor glycosylphosphatidylinorcitol (GPI-anchored). This enables the sperm to penetrate the hyaluronan-rich extracellular matrix of the cumulus cells. The second form is expressed and located in the acrosomal vesicle, a soluble form, which clears the hyaluronan in the ZP rapidly and thereby helps the sperm to reach the oocyte membrane (Brinck, 2000; Stern and Csoka, 2000). Sperm hyaluronidase activity relates significantly to the fertilization rate. The ability of sperm to penetrate a highly viscous solution of sodium hyaluronan is correlated with the motality and fertilization deficiency. Hyaluronan penetration is used as a method to prepare and evaluate the functional competence of human sperm in assisted fertilization programs (Salustri and Fulop, 1998). Two hyaluronidases genes, HYALP1 and SPAM1, are both expressed exclusively in testicular tissues, HYAL3 is highly expressed in testis but also in bone marrow (Csoka et $a l ., 1999)$. These two tissues retain a stem cell-like state for life in the animal but whether or not HYAL3 participates in the process of fertilization is still not known and needs to be elucidated (Stern and Csoka, 2000). A possible participation in fertilization is also not known for HYAL5 an additional hyaluronidase localized almost $100-\mathrm{kb}$ away from the SPAM1 gene (Baba et al., 2002).

\subsubsection{Hyaluronidases in Descensus testis}

Two major forms of a misleaded Descensus testis are known in mammals: Cryptorchidism and hernia.

\section{Cryptorchidism}

During testicular development, the testes descend into the scrotum for a cooler environment to preserve normal spermatogenesis. Cryptorchidism is defined as an absence of at least one testis from the scrotum. Although the other word often used for this interchangeably phenomenon is undescended testis, the terms are not synonymous since cryptorchid testes can also be retractile, ectopic, or absent. Thus, there are 4 types of cryptorchidism: undescended along the path of descent, ectopic testes outside the path of 
descent, retractile testes descended but ascend due to the cremaster reflex (genitofemoral nerve) and absent testes vanished testes (intrauterine testicular torsion) or agenesis distinguished by the presence of Muellerian structure. The molecular aetiology of this syndrome was for a long time unclear. Recently, the role of insulin-like factor-3 (INSL3; alternatively called relaxin-like factor) has been highlighted through the cryptorchid phenotype of mice (Nef and Parada 1999; Zimmermann et al. 1999). In human and in pig several different mutations in the INSL3 gene have been investigated and association studies to the phenotype cryptorchidism undertaken. However, most of this studies exclude that mutations in the INSL3 are the genetic cause for cryptorchidism (e.g. Takahashi et al., 2001; Baker et al., 2002; Knorr et al., 2003), whereas some report a low association (Tomboc et al., 2000). Studies on developmental transcription factors, such as Hoxa-10 in mice, suggest that other specific molecular cascades could also lead to a cryptorchid phenotype (Ivell and Hartung, 2003).

The inheritance of cryptorchidism was investigated in Duroc swine. Two hypotheses were examined by Rothschild et al. (1988): first, that this trait is controlled by homozygosity of a recessive gene at a single locus; second, that it is controlled by homozygosity of recessive genes at two loci. The first hypothesis of a single recessive gene was rejected, but not the two-locus model.

\section{Hernia}

With respect to the reproductive tract two forms of hernia are described: hernia inguinalis and hernia scrotalis: Hernia scrotalis (inguinalis) is a sex-limited (not sexlimited) condition in males (both sexes) that is believed to result from a weakness of the musculature surrounding the inguinal canal, permitting the intestine to drop into the scrotum (inguinal canal). Hernias occur much more frequently on the left side of an individual. The mode of inheritance shows familiar occurrence, but convincing evidence for a single gene inheritance is lacking (Rothschild and Ruvinsky, 1998). Several genes have been suggested to be causative for the disorder along with maternal and environmental influences (Todd See, 2003). A study showed recently that the frequency of inguinal hernia could be increased from $1.7 \%$ to $90 \%$ in only 6 generations (Wolfe, 2002). 


\section{Gubernaculum hyaluronidase and Testicular descent}

The gubernaculum testis is the connection tissue organ that is connected to the caudal pole of the testis and which mediates testicular descent mechanically. During the first phase of descent the gubernaculum grows through the inguinal canal into the future cavity and simultaneously brings the testis to the inguinal canal. During the second phase of descent the gubernaculum condenses and thus promotes the further descent of testis into the scrotum (Wensing et al.,1988). The mechanisms of testicular descent are displayed schematically in Figure 2. To find biological markers for differentiated expression of gubernaculum fibroblasts characteristic for outgrowth or regression of the gubernaculum testis the composition of the tissue with respect to glycosaminoglycans, collagen and DNA was investigated by Fentener van Vlissingen et al. (1989). It became evident that the gubernaculum development with respect to cell proliferation rate, extracellular matrix (ECM) synthesis and degradation is very different during gubernaculums development. The metabolism of hyaluronic acid changed remarkably during testis development. During the first phase of testicular descent (70-80 days of pig fetus), HA synthesis rate exceeds the rate of cell proliferation and concomitant synthesis of sulphated glycosaminoglycans (SGAG), HA, and collagen. In this phase, the development of HA accumulation exceeds the increase in cell number. Cell density is low because of the increase in hydrated space. Regulatory substances that may control testicular descent should control the first phase of gubernaculum development. These factors must exert their effects on the fibroblasts of the gubernaculum testis and influence characteristics of connective tissue growth and differentiation both with respect to cell proliferation and composition of the ECM. The amount of HA diminishes during the second phase, cell density and S-GAG increases, the total amount of HA per gubernaculum decreases dramatically while the concentration of HA only slightly decreases. That might cause the hydrated space to decrease proportionally to the decrease in HA. Concentration of HA per gram of tissue was stable between 70 days of gestation but after 90 days HA decreased steadily, indicating biodegradation. The ratio between HA and DNA increases between 70 and 90 days of gestation and decreases thereafter. The enzymes that act in the biodegradation of HA might feather the second phase of testicular descent. Characteristic for the hyaluronidase in the gubernaculum are the extremely low $\mathrm{pH}$ optimum (2.5-3.5). The enzyme activity per gram of the tissue increases slowly but steadily during the fetal period and at a higher rate postnatally (figure $3 a, b)$. The increase of hyaluronidase between 80 day post conceptionem and date of birth 
was due to the increase of cell density, while the postnatal increase represented increased enzyme activity per cell. The selective degradation of HA was probably due to the net increased lysosomal digestion by hyaluronidase and other enzymes. It acts as a distinct feature of gubernaculum development during the second phase. Biodegradation of HA might therefore be useful as a biological marker of gubernaculum regression.

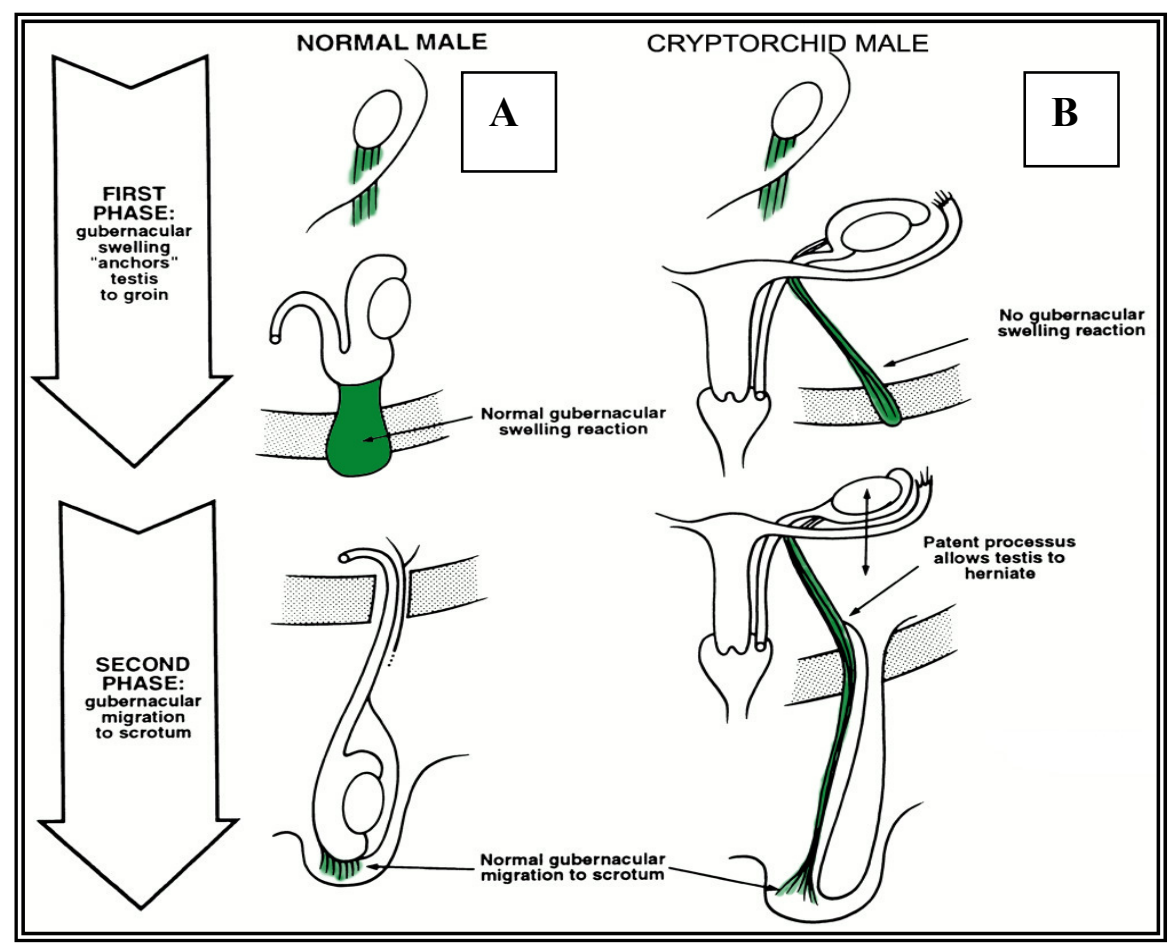

Figure 2: Schema of gonadal descent showing two phases in normal male (A) compared with cryptorchid male (B). Normal development of the processus vaginalis, which is part of the second phase of descent, along with hypermobility of the testis because the gubernaculum is long allows the testis ( \pm ducts) to prolapse into the groin (Adapted from Hutson et al., 1997). 


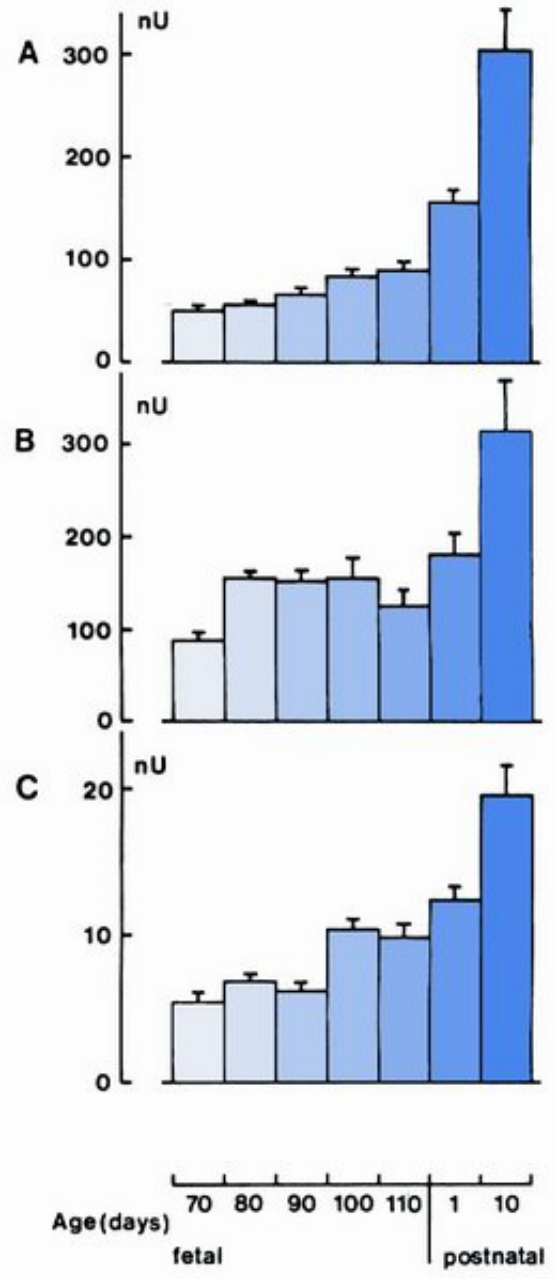

Figure 3a: Hyaluronidase activity $(n U)$ in gubernaculums from male porcine fetuses and neonates of various ages, expressed per gram of wet tissue (A), per mg of DNA in same sample (B), or per $\mathrm{mg}$ of extracted protein (C); (Adapted from Fentener van Vlissingen et al., 1989).

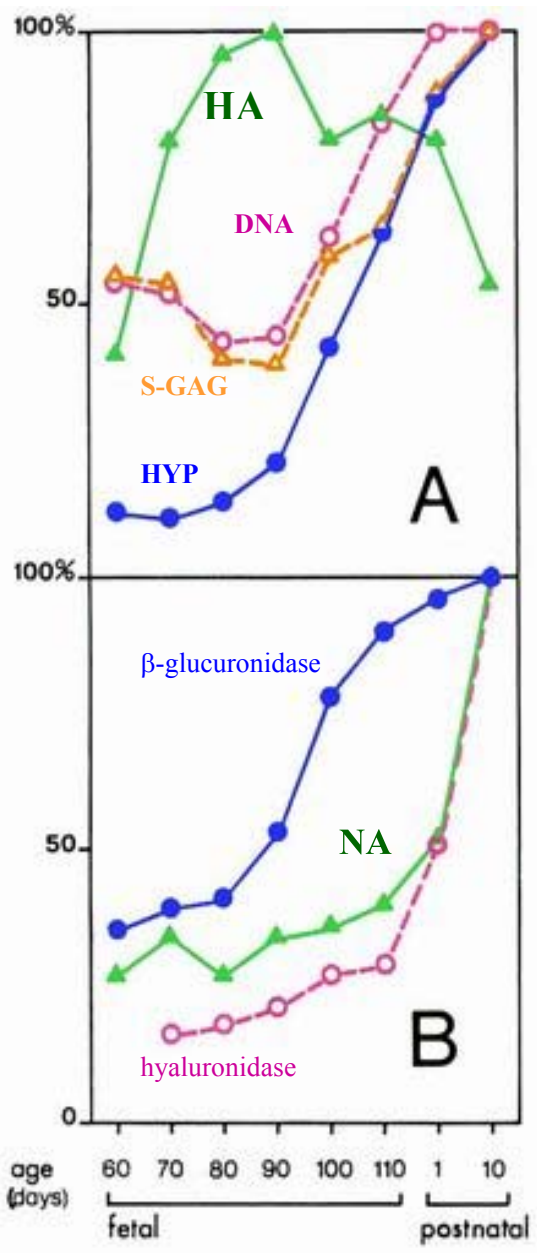

Figure 3b: Relative changes of ECM constituents and DNA (A) and acid hydrolase (B) per $\mathrm{mg}$ of gubernaculum testis tissue during testicular descent. Metric quantity corresponds to 100\%; (Adapted from Fentener van Vlissingen et al., 1989). 


\subsection{MOLECULAR ANALYSIS OF HYALURONIDASE GENES}

\subsubsection{HYAL GENES}

The hyaluronidase genes are also referred to as hyaluronoglucosaminidase $(H Y A L)$. There are six paralogous $H Y A L$ genes known sharing about $40 \%$ identity with one another. HYAL genes are reported in the tumor suppressor gene region (TSG) on HSA3p21 (Wei et al., 1996) and on HSA7q31 (Csoka et al., 1999). This arrangment is due to an original ancient cluster formation, followed by en masse duplication (Stern and Csoka, 2000). On HSA3p21.3, HYAL1, 2 and 3 (also referred to as LUng CAncer1, 2 and 3) are located in a successively narrowed critical gene region, first, to $\sim 370-\mathrm{kb}$, and, more recently, to $\sim 120$ $\mathrm{kb}$ containing the genes CACNA2D2-PL6-101F6-NPRL2-BLU-RASSF1-FUS1-HYAL2HYAL1-FUS2-HYAL3-IFRD2-SEMA3B-GNI2-G17-GNAT1-SEMA3F-G15-G16 (figure 4). This group is the critical tumor homozygous deletion region in lung and breast cancers (Csoka et al., 2001; Kreil 1995; Shuttleworth et al., 2002; Lerman and Minna 2000). Ji et al. (2002) reported that the genes act together to suppress tumor growth through their functional activation of tumor suppressing pathways. The genes' orthologs in mouse are Hyal1, Hyal2, and Hyal3 which have recently been cloned on mouse chromosome $9 F 1-F 2$ (Shuttleworth et al., 2002).

The second group of hyaluronidase genes HYALP1, HYAL4 and SPAM1 is clustered on HSA7q31.3. HYALP1 gene represents an expressed pseudogene, current knowledge indicates that the HYAL4 gene encodes a chondroitinase without any known activity against hyaluronan (Csoka et al., 1999). The third gene in this cluster SPAMI encodes for protein $\mathrm{PH}-20$, an acrosome intact protein. In mouse the chromosomal localization of the second cluster was reported with $6 A 2$ (Stern and Csoka, 2000). 


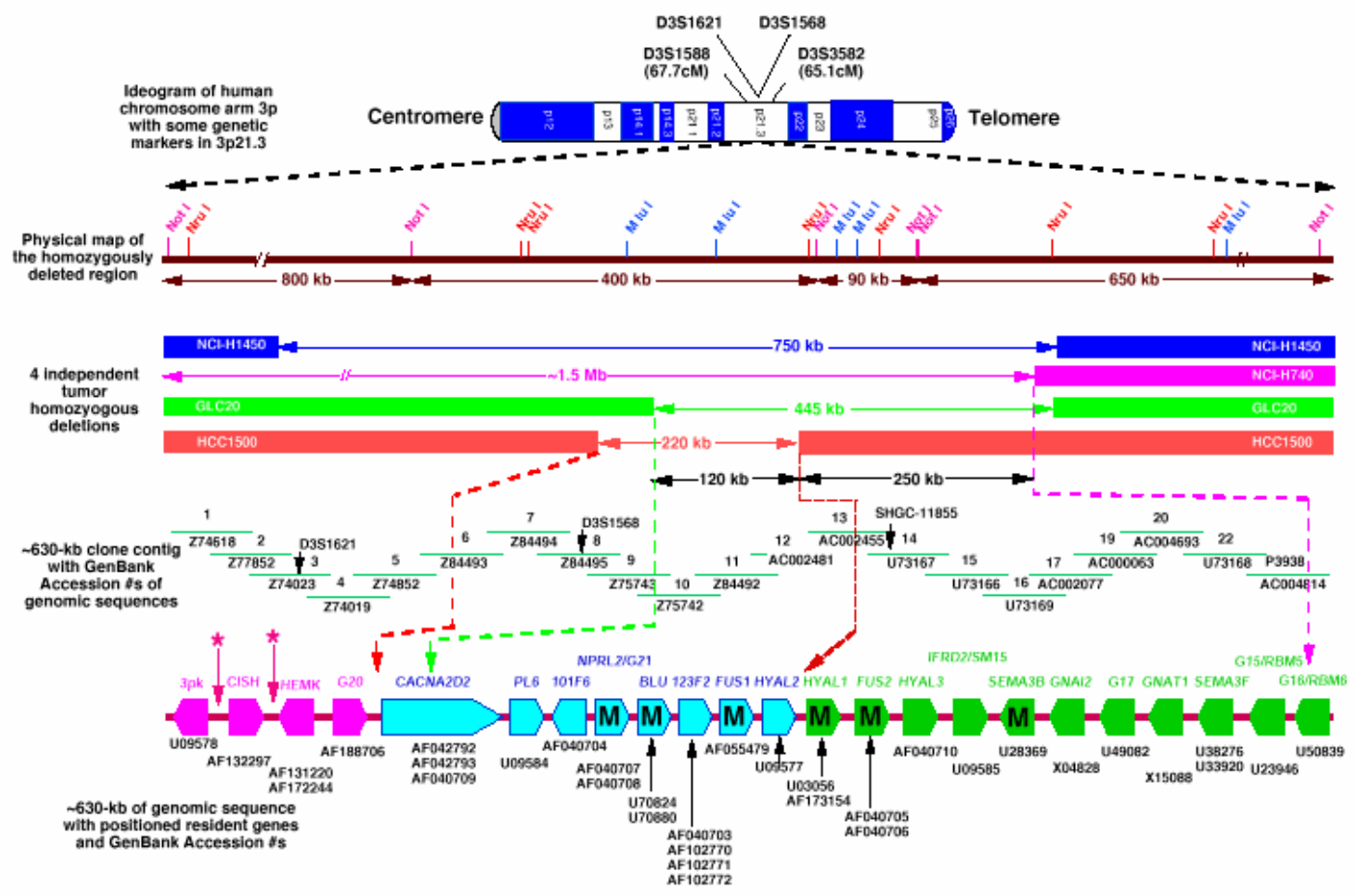

Figure 4: Genetic and physical characterization of the nested homozygous deletion region, lung cancer TSG, provisionally called $L U C A$ on HSA3p21.3. The 630-kb region contains a set of 25 genes identified: 19 of these lie within the $370-\mathrm{kb}$ region and 8 within the nested 120-kb region (blue boxes). The 6 genes outside of the critical region in the centromeric portion are in magenta while the remaining 11 genes still within the rest of the lung nested homozygous deletions (an additional $250 \mathrm{~kb}$ ) are all in green. The six genes that exhibit at least some point or small mutations have an " $\mathrm{M}$ " in their box (Lerman and Minna, 2000).

Expression studies of the human HYAL genes revealed unique tissue-specific patterns. Northern blots showed that HYAL1 and 2 are widely expressed. HYAL3 is differentially expressed in bone marrow and testis while HYAL4 is differentially expressed in placenta and skeletal muscle. PH20 was detected only in testis. For HYALP1, the signals found in thyroid and adrenal glands after a long exposure time demonstrate that it is an expressed pseudogene (Csoka et al., 1999). In mouse, expression profiles of Hyall, Hyal2 and PH2O are similar to human but mouse Hyal3 was broader expressed than in human. Later, reverse transcription-PCR demonstrated that some of the larger Hyall transcripts seen on the Northern blot were the result of cotranscription of Hyall with downstream genes, Fus2 or Hyal3 (Shuttleworth et al., 2002). Regulation of protein synthesis is a multi-component and multi-step process involving protein, RNA and low 
molecular weight ligands. Protein: RNA-interactions are dependent on the sequence and structure of mRNA. Under different physiological conditions which may be influenced by the cellular environment, virus infection or the stage of cell cycle, an mRNA may be either selectively translated or stored as an inactive protein: RNA complex (mRNP) (Woodley, 2002). Regulation of hyaluronidase activity is due to alternative mRNA splicing. The RTPCR analysis on RNA extracted from a bladder cancer cell line, bladder tissues, lymph nodes positive for tumor, and normal kidney tissue showed alternative splicing of HYAL1 and HYAL3 in control of HYAL activities (Lokeshwar et al., 2002).

\subsubsection{Genes of the human hyaluronidase gene cluster on chromosome $3 q 21.3$}

\section{1) HYAL1}

The human HYAL1 gene has been described as plasma hyaloronidase encoding 435 amino acids (aa) (Genbank Acc. No: AAD04190); Frost et al., 1997) while the mouse Hyall codes for a protein of 462 aa (Genbank Acc. No: AAC15949; Csoka et al., 1998) that is $79 \%$ identical to the human sequence. The human gene spanning $\sim 3.5-\mathrm{kb}$ contains 4 exons coding for a $2.6 \mathrm{~kb}$ mRNA is well expressed in all analyzed human tissues including lung and is abundantly represented in EST databases from normal and tumor tissues (Lerman and Minna, 2000). The tissue expression profile for HYAL1 was similar in mice and human with highest levels of expression in liver followed by kidney and skin (Csoka et al.,1998; Shuttleworth et al., 2002).

HA in prostate cancer increased 3-8-fold compared to normal tissues. The stromalepithelial HA and HYAL1 expression may promote angiogenesis. High HA was observed in tumor-associated stroma and HYAL1 in tumor cell increases with tumor growth and metastasis (Lokeshwar et al., 2001). Thus, HYAL1 is the major tumor-derived HAase expressed in bladder and prostate cancer tissues. It has a optimum $\mathrm{pH}$ range of 4.0-4.3, and the enzyme is $50-80 \%$ active at $\mathrm{pH} 4.5$ (Lokeshwar et al., 2001).

Several mRNA splice variants (figure 5) were later found in bladder and prostate cancer cells and in bladder and kidney tissues (Lokeshwar et al., 2002). The authors describe finally the HYAL1 wild type (wt) cDNA and a total of five variants (vt) encoding proteins of 405, 253, 209, 176, and 96 aa. Common for the six cDNAs is the spliced out region between nucleotides, 110 to 596 whereas the differences between variants are due to other splice sites throughout the cDNA. Further experiments with respect to HAase activity revealed no activity for variants 3, 4, and 5. Measurable HAase activity showed HYAL1 wt, but vt 1 lacking only 30 aa (compared with wt) has no activity. The vt 2 protein on the 
other site shows a reduced activity of 90\% compared with the wt. Lokeshwar et al. (2002) conclude therefore that the 30 aa sequence between aa 300 to 331 may be crucial for HA activity. They also postulate that expression of functional active HAases in different tissues is regulated by alternative splicing and they stress that expression of the wt cDNA in high grade bladder tumor tissues and as well as in invasive bladder cancer cells makes the HAase as a marker for tumor progression regardless of its grade.

Another effect of mutations in the HYAL1 gene was described by Triggs-Raine et al. (1999) who identified two mutations in the HYAL1 alleles of a patient with a deficiency of serum hyaluronidase designated as mucopolysaccharidosis IX. A $1412 \mathrm{G} \rightarrow$ A mutation introduces a nonconservative amino acid substitution (Glu268Lys) in a putative active site residue and they also found a complex intragenic rearrangement called 1361del37ins 14 that results in a premature termination codon. 


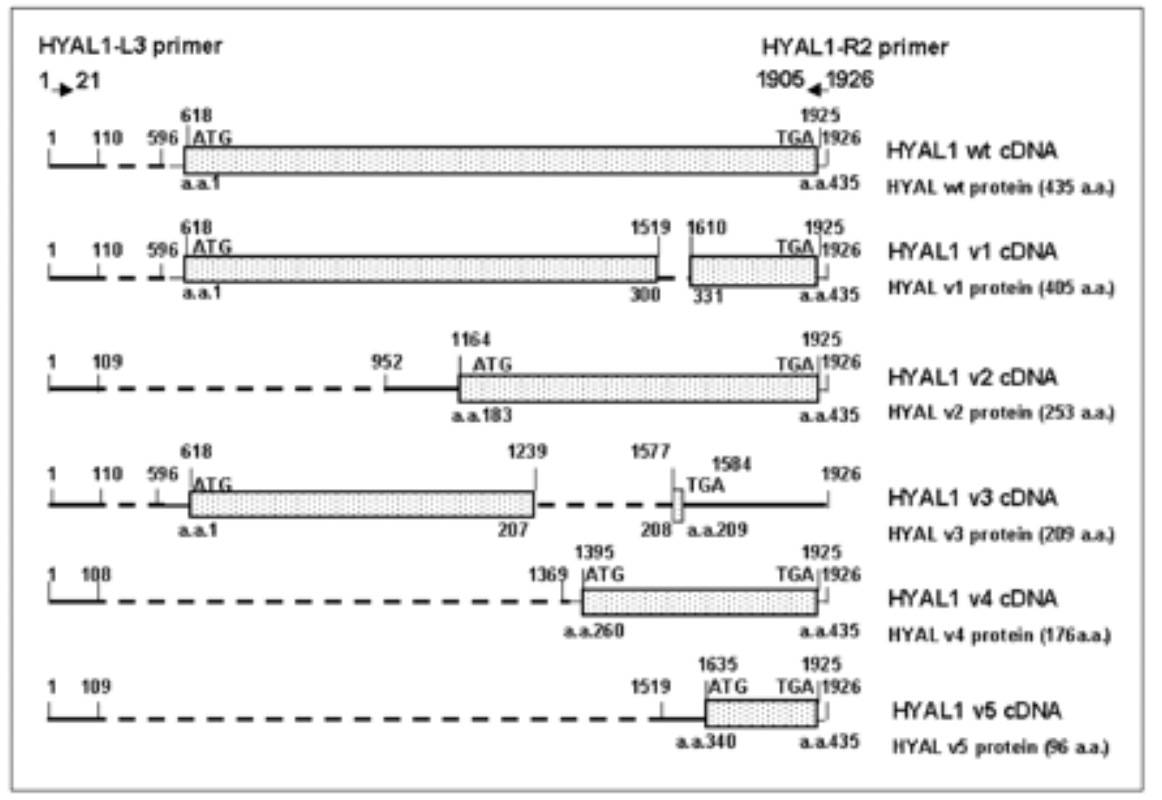

Figure 5: A schematic representation of the $H Y A L 1$ splice variants. The figure shows HYAL1wt and different splice variant cDNAs. The coding region is shown as a dotted block. The dashed line shows the region that is spliced out, and solid line represents untranslated regions. Each splice junction is marked by the nucleotides at the $5^{\prime}$ and $3^{\prime}$ boundaries that are joined because of splicing. The translation initiation and termination codons for HYAL1wt and HYAL1 variants are AF502904 (HYAL1v1), AF502905 (HYAL1v2), AF502906 (HYAL1v3), AF502907 (HYAL1v4), AF502908 (HYAL1v5), AF502909 (Lokeshwar et al., 2002).

\section{2) HYAL2}

HYAL2 was originally designated as the lysosomal HAase as it cleaves high molecular mass HA into $20-\mathrm{kDa}$ HA fragments. It has been identified as a putative lung cancer tumor suppressor gene. HYAL2 is not among the small subset of the 19 genes that display mutational patterns characteristic of the classical pattern of loss of tumor suppressor function (Lerman and Minna, 2000). Human HYAL2 encodes a protein of 473 aa (GenBank Acc. No: U09577). Two transcription variants of human HYAL2 are observed in Gene Bank database, HYAL2v1 of 1,848-bp (GenBank Acc. No: NM_003773) and HYAL2 v2 of 1,918-bp (GenBank Acc. No: NM_033158) (Wei et al., 1996). The variant v1 differs by an alternative first exon in the 5' UTR while it encodes the same protein as transcript variant 2 (v2). Human HYAL2 is expressed in many cells but not in adult brain. 
The enzyme has an acidic pH-optimum below 4 with an activity that is considerably lower than observed for other types of hyaluronidases (Lepperdinger et al., 1998).

The role of the lysosomal hyaluronidase on tumor invasion was investigated by overexpression of HYAL2 in astrocytoma cells. By this overexpression, intracerebral tumor growth was dramatically accelerated, but the same cells formed s.c tumors within the same time as parental cells. Thus, it seems that the interaction of the HYAL2expressing tumor cells and the hyalurunan-containig extracellular matrix mediates this specifically in the brain (Novek et al., 1999).

The ovine HYAL2 cDNA was also cloned (Dirks et al., 2002; GenBank Acc. No: AF411974). The HYAL2 encoded protein functions as an efficient receptor for both Jaagsiekte sheep retrovirus (JSRV) and Enzootic nasal tumor virus (ENTV). The JSRV and ENTV envelope (Env) proteins cause cancer by inhibiting the tumor suppressor activity of HYAL2. In the mouse model, expression of human HYAL2 suppresses Envmediated transformation by reduction of Env-protein levels by an increasing Env degradation (Liu et al., 2003). The Enzootic nasal tumor virus induces nasal epithelial cancer in infected sheep. It is closely related to JSRV, which also causes cancer in sheep but in the epithelial cells of the lower airways and alveoli (Dirks et al., 2002). Besides its role as a lysosomal hyaluronidase, HYAL2 is a glycosylphosphatidylinositol (GPI)anchored cell-surface receptor for the ovine betaretrovirus JSRV that causes contagious cancers in lungs and upper airways of sheep and goats with its relationship to human bronchiolo-alveolar carcinoma (Rai et al., 2001). Sheep was therefore used as an animal model, to explore the possible use of Ovine pulmonary adenocarcinoma (OPA) as a tool to investigate the mechanisms of pulmonary carcinogenesis, and to underline the similarities between the OPA and some forms of human lung adenocarcinoma (Palmarini and Fan, 2001).

\section{3) HYAL3}

HYAL3 has been detected in brain and liver tissues, its protein product is still uncharacterized. The HYAL3 nucleotide sequence reveals that this gene contains 4 exons separated by 3 introns. Lokeshwar et al. (2002) described for HYAL3 splice variants after RT-PCR in different tissues with sizes of $1.5,1.4,0.7$, and $0.6 \mathrm{~kb}$. The $1.5 \mathrm{~kb}$ HYAL3 wild type (wt) was amplified from normal kidney tissue RNA, the $1.4 \mathrm{~kb}$ HYALl3 variant1 (v1) from kidney tissue that is detectable in many bladder cancer cell lines. The major PCR amplification product which is present in all bladder cancer cells, tissues, and lymph node 
specimens is the $0.6 \mathrm{~kb} H Y A L 3$ variant3 (v3) whereas the $0.7 \mathrm{~kb} H Y A L 3$ variant2 (v2) is present in the kidney tissue. In vitro translation and translation of HYAL3wt and variant proteins generate polypeptide chains with molecular masses of $\sim 48, \sim 45, \sim 20$ and $\sim 16 \mathrm{kDa}$, respectively. The $\mathrm{pH}$ optimum of HYAL3 HAase activities is 4.2 and only the wt is active, whereas all variants are enzymatically inactive. It is concluded that the putative catalytic site possibly Glu at position 266, and the 30 aa stretch from aa 299 to 328 are critical for HAase activity of the HYAL3 protein. HYAL3v1 has no HAase activity because of the lack of the 30 aa sequence from aa 299 to 328 but it retains the putative enzyme catalytic site (Asp at position 127 and Glu at 129) and Glu at position 266 which may be generally important for HAase activity. The Hyal3v2 retains the 30 aa sequence and Glu266 but lacks the putative enzyme catalytic site is also enzymatically inactive. The Hyal3v3 that contain only Glu266 and lacks both the putative enzyme catalytic site and the 30 aa sequence has no HAase activity as well (Lokeshwar et al. 2002) (figure 6).

Different bladder and lymph node specimens and cells show differences in the pattern and type of HYAL1 and HYAL3 splice variants that are expressed. It is possible that the heterogeneous expression of the HYAL1 and HYAL3 variants may be related to the different biological behavior of different bladder tumors. Lerman and Minna (2000) reported that HYAL3 RNA was not expressed in any lung cancer cell lines. Its lack of mutation and none-expression in normal lung cells makes HYAL3 a less attractive TSG candidate.

In both HYAL1 and HYAL3 proteins the loss of the 30 aa sequence results in the loss of HAase activity. It is assumed that the loss of the sequence results in a loss of substrate binding as it is critical for HAase structure and activity. Studies on the HYAL3 splice variants revealed that the 30 aa sequence is coded by one single independent exon and also that the 90-bp long independent exon (e.g missing in HYAL1vl) in both genes seems to encode for the protein sequence that is critical for HAase activity. The observations and the elevation of HAase levels in bladder and prostate tumors which have high levels of HAase activity suggest that HYAL1 may play a role in promoting tumor progression. Normal cells may suppress the HAase activity of HYAL1 by generating HYAL1 splice variants that encode an inactive enzyme. The expression of HYAL3, in bladder tumor cells and tissue including prostate cancer cells reveal that the major HYAL3 transcript is HYAL3v3, which is enzymatically inactive. And the minor transcript is HYAL3v1 (Lokeshwar et al., 2002). It is possible that expression relates to the biological behavior of cancer, in carcinogenesis, biological activity and malignant potential for each 
type of cancer. It may be associated with distinctive molecular and genetic alterations (Lee and Droller, 2000). Therefore, the function of these enzymatically inactive Hyal3 variant proteins remains unclear. In the mouse model, the order of the genes HYAL2, HYAL1, HYAL3 was found to be conserved. A gene encoding an $\mathrm{N}$-acetyltransferase, FUS2, was found completely within the first intron of HYAL3. Northern blot analyses of mouse hyaluronidases revealed multiple transcripts that result from alternative splicing as well as from co-transcription of HYAL1 with FUS2 and HYAL1 with HYAL3. These complexities must be taken into consideration in strategies for the development of mouse models of hyaluronidase deficiency and in understanding the roles of these genes in health and when mutated (Natowicz and Triggs-Raine, 2001).

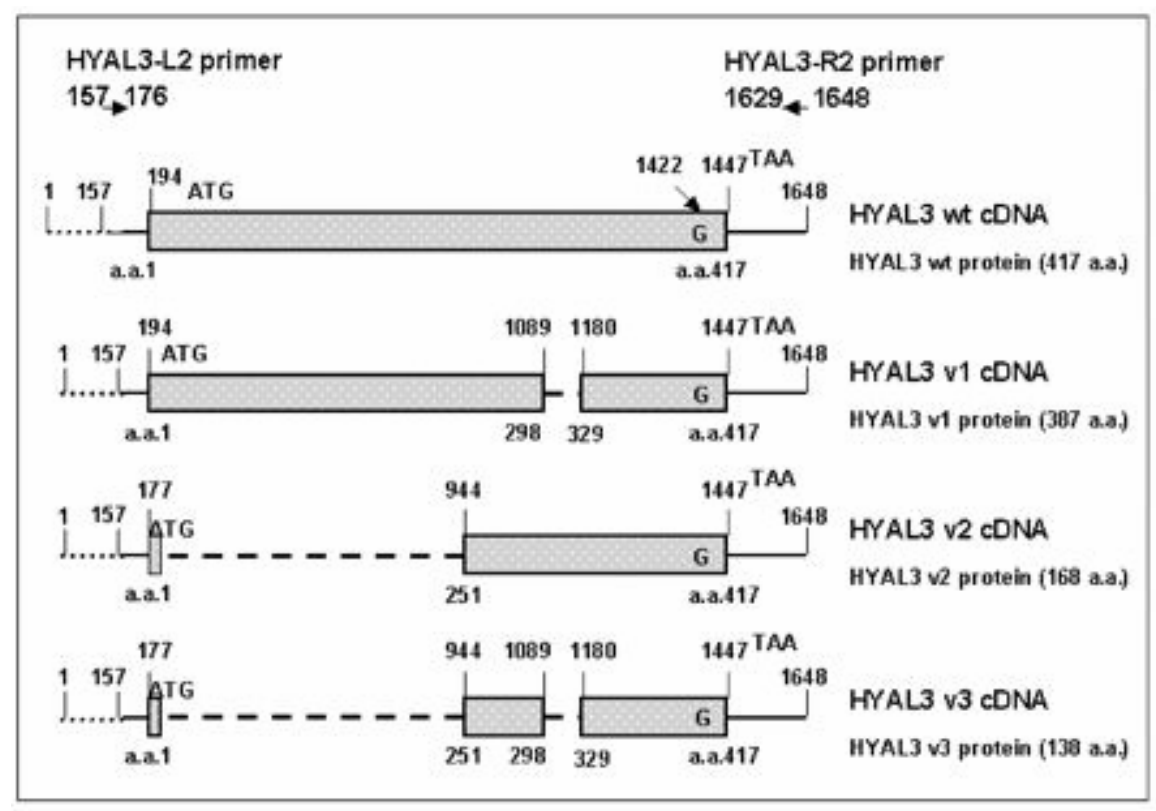

Figure 6: A schematic representation of the HYAL3 splice variants. The figure shows HYAL3wt and different splice variant cDNAs; AF502909 (HYAL3v1), AF502910 (HYAL3v2), AF502911 (HYAL3v3), and AF502912 (HYAL3wt). The coding region is shown as a dotted block. The dashed line shows the region that is spliced out, and the solid line represents untranslated regions. Each splice junction is marked by the nucleotides at the 5' and 3' boundaries that are joined because of splicing (Lokeshwar et al., 2002). 


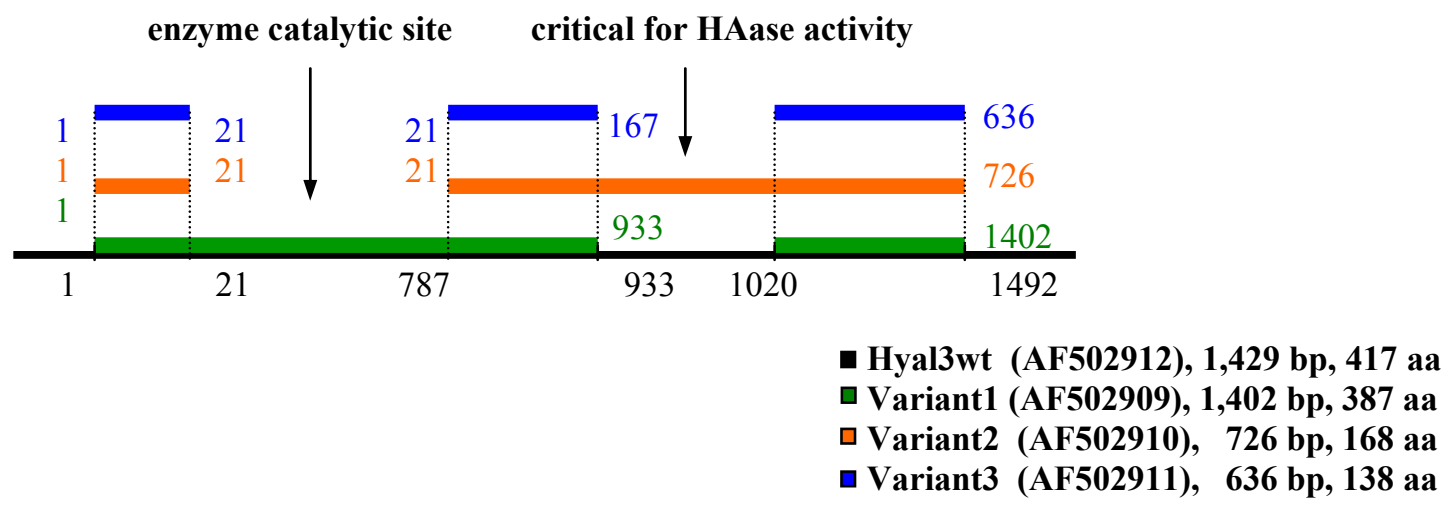

Figure 7: $H Y A L 3$ alternative splicing of a single independent exon for control expression and enzymatically active hyaluronidase.

\section{4) Lung cancer candidate (FUS1) gene}

The FUS1 gene was discovered experimentally by screening cDNA libraries with a genomic fragment from cosmids $L U C A 12$ and $L U C A 13$. Human FUS1 is coding for a 1691-bp mRNA (Genbank Acc. No: AF055479) with a 110-aa protein (Genbank Acc. No: NP_009206). The gene space is about 3.3-kb separated in 3 exons. The gene name "FUS" was given as the sequence acted as fusion between Luca12 and Luca13 at the time of its isolation. Expression of the gene by Northern Blot displayed a 1.8-kb transcript strongest expressed in heart, lung, skeletal muscle, kidney and pancreas (Lerman and Minna, 2000). Mutation of FUS1 is infrequent in lung cancers but there is no evidence for FUS1 promoter region methylation. Overexpression of the FUS1 gene leads to G1 arrest and growth inhibition of lung cancer cells (Kondo et al., 2001). The FUS1 protein shows to inhibit the growth of tumors and greatly reduces the spread of lung cancer in mice. Thus, this gene may provide a novel method of selectively destroying cancer cells in humans. FUS1 was also used in gene transfer for the Non-Small-Cell Lung Cancer, drug DOTAP; CholesterolFus1 (Anderson, 2003). 


\section{5) Putative tumor suppressor gene FUS2}

The FUS2 gene was discovered experimentally by screening cDNA libraries with a genomic fragment from cosmid LUCA14. It is an intronless single copy gene coding for a 1.9-kb mRNA (GenBank Acc. No: AF040705) expressed in normal human tissues including lung. An alternatively spliced form (Genbank Acc. No: AF040706) exists that results in the same predicted amino acid sequence (Lerman and Minna, 2000). The mouse ortholog was discovered in mouse EST databases (Genbank Acc. No: AA051756, AA051686, AI425576, AA833145). The gene product encodes N-acetyltransferase 6 and FUS2 is therefore alternatively called Nat6 (EC 2.3.1). Computer analysis predicted the existence of the catalytic domain specific for acetyltransferases (GNAT) and a proline rich domain in FUS2. FUS2 localizes to the cytoplasm and functions to acetylate the Nterminus of proteins using a ping-pong mechanism with specificity for substrates (Zegerman et al., 2000). Mouse FUS2 has been reported to be in cotranscription with HYAL 1 and HYAL3 genes but the tissue distribution of FUS2 and HYAL3 in mouse differs from that in humans (Shuttleworth et al., 2002). Defects in Nat6 are found in non-small cell lung cancer (nsclc) cell lines. Missense mutations were detected in lung cancer cell lines that makes FUS2 an attractive candidate for future TSG functional studies (Lerman and Minna, 2000; Wei et al., 1996).

The FUS2 gene is also well characterized in yeast (Saccharomyces cerevisiae), as a nuclear fusion protein. Its functions in promoting cell fusion during zygote formation at optimum pH 9.2 (GeneDB; YMR232W). Cell fusion is the process by which the plasma membranes of two cells fuse to establish cytoplasmic continuity. Fusion events mediate housekeeping functions such as endocytosis, constitutive secretion and also occur in special cells as in regulated exocytosis of hormones. Fusion events are also associated with disease states: the formation of giant cells during inflammatory reactions, or the entry of all enveloped virus into host cells. In many fusion events, the leaflets that face to the cytoplasm make the initial contact; this category encompasses fusion of intracellular macromolecular carrier vesicles with their target organelles. As an example the protein responsible for influenza virus fusion is a characterized hemagglutinin. A combination of factors has contributed to the prominence of hemagglutinin-mediated fusion as a model membrane fusion system (shown in figures 8A, B) (White, 1992). The mating pathway in yeast provides a model for signaling-controlled changes at the cell surface (Alia and Marsh, 1998) as well as the process by which two haploid cells fuse to form a diploid zygote (Gammie et al., 1998) that can be used in sperm-egg interaction model. The fusion 
of egg and sperm to form a zygote and the fusion of muscle cell precursors to generate multinucleate syncytia of muscle fibers are two examples wherein cell fusion is a key process. Mutations of FUS2 showing to be specifically defective in cell fusion, appear to be resulting from remodeling their cell wall. The mutant also has strong defects in karyogamy and fails to orient microtubules between parental nuclei in zygotes (Elion et al., 1995).
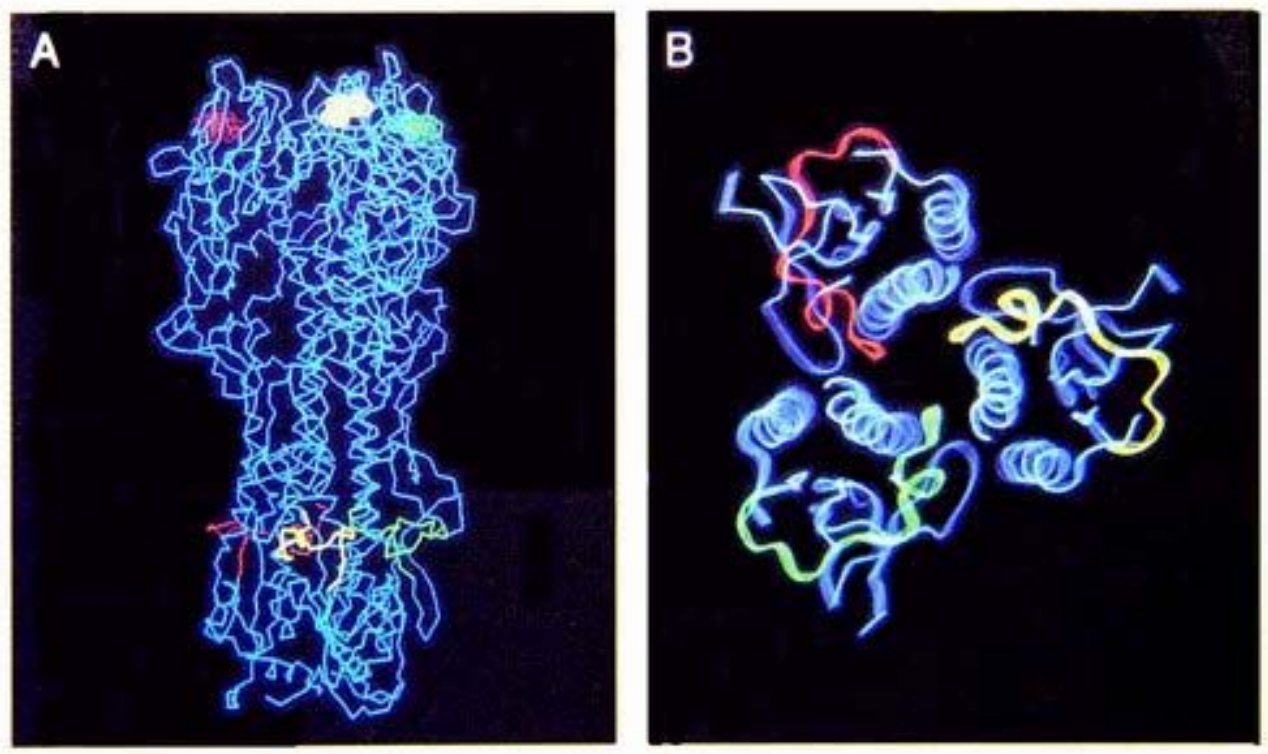

Figure 8: The influenza hemagglutinin. The carbon backbone of the hemagglutinin trimer is displayed with the three fusion peptides, located in the stem of the molecule and molecular surfaces of sialic acid residues are shown in the receptor binding sites if the globular head domains (highlight in red, yellow and green) (figure A). Figure B shows ribbon diagram of the hemagglutinin trimer cross section highlighting the three fusion peptides (Adapted from White, 1992). This model has suggested potential fusion proteins and several of this assignment have been supported by site-specific mutagenesis. 


\subsection{Genes of the hyaluronidase gene cluster in pigs}

\subsubsection{Genes and localization}

Only one porcine hyaluronidase (Genbank Acc. No: SSU14751) has been identified and deposited in the NCBI-database. The enzyme isolated from liver encodes for a 459-aa protein (Genbank Acc.No; AAC48457) and reveals identity with hemopexin, a serum heme-binding serum protein (Zhu et al., 1994). Recently, it proved that the claim of identity with hemopexin was based on an artifact which is due to dye exclusion and the high levels of contamination (Frost et al., 1996).

Lahbib-Mansais et al. (1999) used an human LUCA1-EST and ZOO-PCR to map the porcine LUCA1 (LUCA1 was formerly used as term for HYAL1; Lepperdinger et al., 1998) gene to SSC13q23-(1/2)q41. Comparative mapping reveals homology between human chromosomes 3 and 21 to pig chromosome 13 (figure 9).

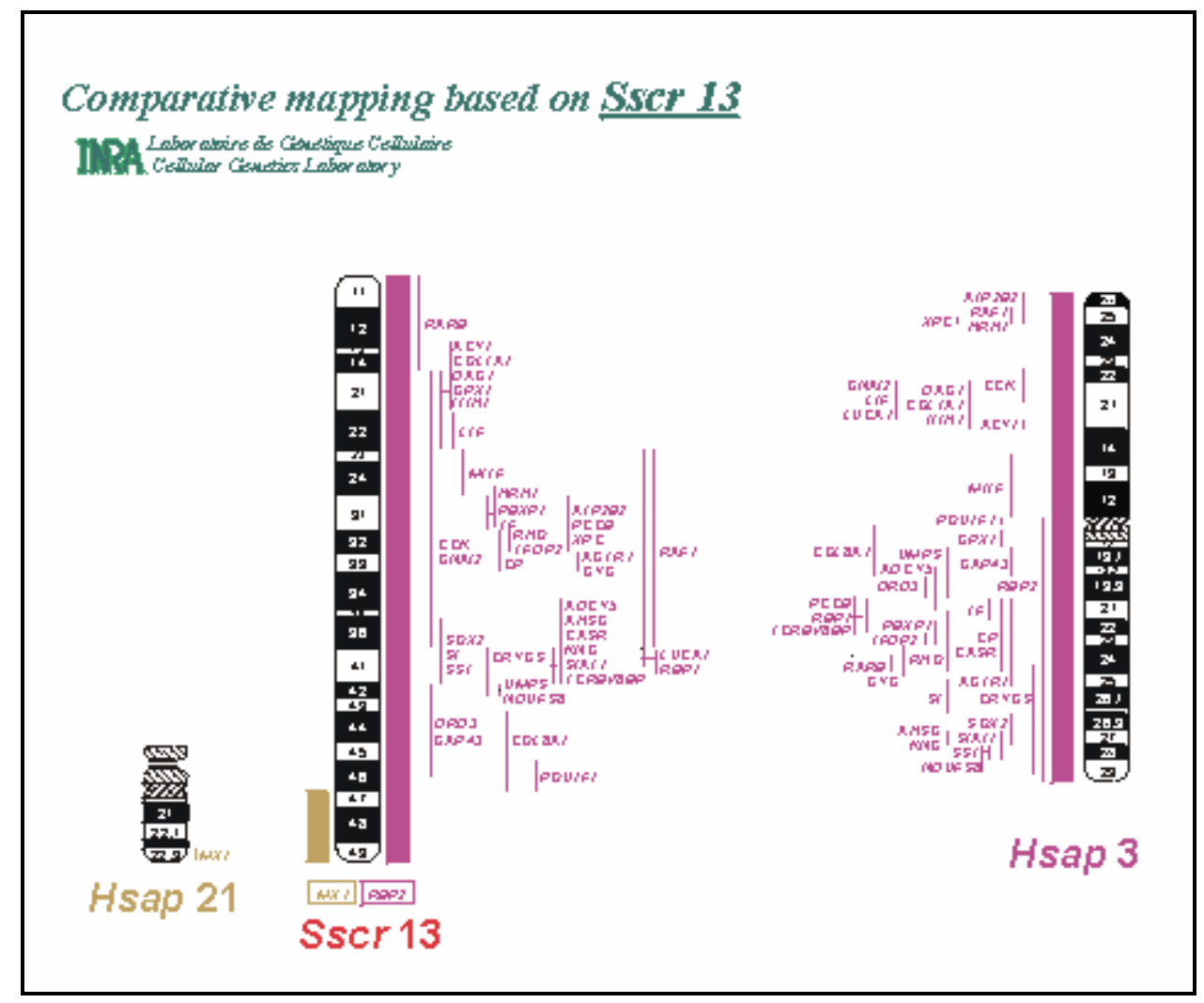

Figure 9: Correspondences between porcine chromosome 13 and human chromosomes 3 and 21. The map shows the LUCA1 gene on SSC13q23-(1/2)q41 (Lahbib-Mansais et al., 1999) which corresponds to HSA3q21.3 (Lerman and Minna, 2000) (http://www.toulouse.inra.fr/lgc/pig/compare/SSCHTML/SSC13B.HTML). 


\subsubsection{Associations between hyaluronidases and pigs}

Hyaluronidase research activities in the pig area focus on food safety control against bacteria, nematodes and denuded oocytes and for in vitro fertilization (Swain and Krisher, 2002). In medical research, studies of hyaluronidase in the porcine aortic heart valve were done to use the results in heart valve replacement surgery. It was hypothesized that the enzymatic mechanisms may be responsible for glycosaminoglycans within the extracellular matrix of bioprosthetic heart valves degeneration (Simionescu et al., 2003).

The nematode Ascaris suum is a threat to public health because the worm is infectious for humans as well (Urban et al., 1998). Hyaluronidase is released by A. suum and is required for gastrointestinal mucosal invasion (Hotez et al., 1992). The worm is responsible for significant economic losses by reducing production efficiency and causing organ condemnations at slaughter due to pathology produced by larval stages L3 and L4 (Rhoads et al., 2001). Surveys in a organic pig herd recorded in a period from March to October 1999 showed that the pigs were naturally infected with A. suum (28\% of weaners, $33 \%$ of fatterners, $14 \%$ of saws). The Ascaris infective eggs were found in $14 \%$ of solid sample from saw pastures and in 35\% from slaughter pig paratus (Carstensen et al., 2002). Furthermore, chickens and pigs can be the transporting host for the human parasite equivalents (Olsen et al., 2001). Thus, the infections of roundworm depends on many factors such as environmental conditions larval development in the egg and egg survival, age of the host, breed, husbandry system, hygiene and treatment schedule (Okulewicz et al., 2002). 


\section{REFERENCES}

Alia L and Marsh L (1998) A Role for a Protease in Morphogenic Responses during Yeast Cell Fusion. Cell Biol., 142,1473-1485.

Anderson MD (2003) Phase I Study Of Intravenous DOTAP: Cholesterol-Fus1 Liposome Complex (DOTAP:Chol-fus1) in Patients with advanced Non-Small Cell Lung Cancer (NSCLC) Previously Treated With Chemotherapy (Protocol \#0201-513). MD Anderson Cancer Center, Houston, Texas, United States (at:http://www.webconferences.com/nihoba/2002mar7/RACALL3-07-02/ppframe.html).

Baba D, Kashiwabara S, Honda A, Yamagata K, Wu Q, Ikawa M, Okabe M and Baba T (2002) Mouse sperm lacking cell surface hyaluronidase PH-20 capass though the layer of cumulus cells and fertilize the egg. J Biol Chem., 277, 30310-30314.

Baker LA, Nef S, Nguyen MT, Stapleton R, Pohl H, and Parada LF (2002) The insulin-3 gene: lack of a genetic basis for human cryptorchidism. J Urol., 167, 2534-2537.

Brinck J (2000) The expression and regulation of hyaluronan syntases and their role in glycosaminoglycan synthesis. Acta Universitasis Upsaliensis. Comprehensive Summaries of Uppsala Dissertations from the Faculty of Medicine 955. (63) Uppsala. ISBN 91-554-4806-2.

Buschauer A (2003) Hyaluronidase as an additive in cancer chemotherapy. Institut für Pharmazie, Regensburg University (at: http:/www.uni-regensburg.de/ Fakultaeten/nat_Fak_IV/Pharmazie/buschauer/research/hyaseadditive.html).

Carstensen L, Vaarst M and Roepstorff A (2002) Helminth infections in Danish organic swine herds. Vet Parasitol., 106, 253-264.

Chang NS (1998) Transforming growth factor-beta protection of cancer cells against tumor necrosis factor cytotoxicity is counteracted by hyaluronidase. Int. J. Mol. Med., 2, 653-659.

CIRVAL (2003) Centre International de Ressources et de Valorisation de L'information des Filieres Laitieres Petits ruminants (at: http://www.cirval.asso.fr/publication/tintenna/t18/enteroart.html).

Csoka TB, Frost GI, Wong T and Stern R (1997) Purification and microsequencing of hyaluronidase isozymes from human urine. FEBS Letters, 417, 307-310.

Csoka TB, Frost GI, Heng HH, Scherer SW, Mohapatra G and Stern R (1998) The hyaluronidase gene HYAL1 maps to chromosome 3p21.2-p21.3 in human and 9F1F2 in mouse, a conserved candidate tumor suppressor Locus. Genomics, 48, 63-70.

Csoka AB, Scherer SW and Stern R (1999) Expression analysis of six paralogous human hyaluronidase genes clustered on chromosomes $3 \mathrm{p} 21$ and 7q31. Genomics, 60, 356-361.

Csoka AB, Frost GI and Stern R (2001) The six hyaluronidase-like genes in the human and mouse genomes. Matrix Biol., 20, 499-508. 
De Maeyer E and De Maeyer-Guignard J (1992) The growth rate of two transplantable murine tumors, 3LL lung carcinomar and B16F10 melanoma, is influenced by Hyal1, a locus determining hyaluronidase levels and polymorphism. Int. L. Cancer, 19, 657-660.

Dirks C, Duh FM, Rai SK, Lerman MI and Miller AD (2002) Mechanism of cell entry and transformation by enzootic nasal tumor virus. J Virol., 76, 2141-2149.

Elion EA, Trueheart J and Fink GR. (1995) Fus2 localizes near the site of cell fusion and is required for both cell fusion and nuclear alignment during zygote formation. J Cell Biol., 130, 1283-1296.

Fentener van Vlissingen JM, van Zoelen EJJ, Ursem PJF, Wensing CJG (1989) In vitro model of the first phase of testicular descent: identification of a low molecular weight factor from fetal testis involved in proliferation of gubernaculum testis cells and distinct from specified polypeptide growth factors and fetal gonadal hormones. Endocrinology, 123, 2868-2877.

Frost GI, Csoka T and Stern R (1996) The hyaluronidase: A Chemical, Biological and clinical overview. Trends Glycosci. Glycotechnol, 8, 419-434.

Frost GI, Csoka T, Wong T and Stern R (1997) Purifucation, cloning, and expression of human plasma hyaluronidase. Biochem and Biophysic Res Comm., 236, 10-15.

Gmachl M and Kreil G (1993) Bee venom hyaluronidase is homologous to a membrane protein of mammalian sperm. Proc. Natl. Acad. Sci., 90, 3569-3573.

Gammie AE, Brizzio V and Rose MD (1998) Distinct morphological phenotypes of cell fusion mutants. Mol Biol Cell., 9,1395-410.

Holstein AF, Engel W and Adham IM (1999) Targeted disruption of the INSL3 gene causes bilateral cryptorchidism. Mol. Endocrinol., 13, 681-691.

Hotez P, Narasimhan S, Haggerty J, Milstone L, HopaleV, Schad GA and Richargs FF (1992) Hyaluronidase from infective Ancylostoma hookwarm larvae and its possible function as a virulence factor in tissue invasion and in cutaneous larva migrans. Infect Immun., 60, 1018-1023.

Hutson JM, Hastrorpe S and Heyns CF (1997) Endocrine Reviews, 18, 259-280.

Ivell R and Hartung S (2003) The molecular basis of cryptorchidism. Molecular Human Reproduction, 9, 175-181.

Jacobson A (2002) Regulation of hyaluronan biosynthesis: Expression in vitro and importance for tumor progression. Doctoral thesis, Department of Medical Biochemistry and Microbiology, Uppsala University.

Ji L, Nishizaki M, Gao B, Burbee D, Kondo M, Kamibayashi C, Xu K, Yen N, Atkinson EN, Fang B, Lerman MI, Roth JA and Minna JD (2002) Expression of Several Genes in the Human Chromosome 3p21.3 Homozygous Deletion Region by an Adenovirus Vector Results in Tumor Suppressor Activities in Vitro and in Vivo. Cancer Research., 62, 2715-2720. 
Kathryn JM, and Victor DV (2001) Glycobiology of sperm-egg interactions in deuterostomes. Glycobiology, 11, 37R-43R.

Knorr C, Taeubert H, Peters U and Brenig B (2004) Characterization of two SNPs (Single Nucleotide Polymorphisms) in the porcine INSL3 gene and their exclusion as a common genetic basis of hernia inguinalis in pigs. Biochemical Genetics, 42, 11-19.

Knudson W (1996) Tumor-associated hyaluronan providing an extracellular matrix that facilitates invasion. American J of Pathology, 4, 1721-1725.

Knudson W and Knudson CB (1995) Overproduction of hyaluronan in the tumor stroma. Tumor Matrix Biology. Edited by R Adany. Boca Raton, FL, CRC Press, 55-79.

Kondo M, Ji L, Kamibayashi C, Tomizawa Y, Randle D, Sekido Y, Yokota J, Kashuba V, Zabarovsky E, Kuzmin I, Lerman M, Roth J and Minna JD (2001) Overexpression of candidate tumor suppressor gene FUS1 isolated from the $3 \mathrm{p} 21.3$ homozygous deletion region leads to G1 arrest and growth inhibition of lung cancer cells. Oncogene, 20, 6258-6262.

Kreil G(1995) Hyaluronidase: a group of neglected enzymes. Protein Sci., 4, 1666-1669.

Krishnapillai AM, Taylor KDA, Morris AFJ and Quantick PC (1999) Chracterisation of Norway lobster (Nephrops norvegicus) hyaluronidase and comparision with sheep and bovine testicular hyaluronidase. Food Chemistry, 65, 515-521.

Lahbib-Mansais Y, Dalias G, Milan D, Yerle M, Robic A, Gyapay G, and Gellin J (1999) A successful strategy for comparative mapping with human ESTs: 65 new region assignments in the pig. Mammal Genome, 10, 145-153.

Laurent TC and Fraser JR (1992) Hyaluronan. FASEB J., 6, 2397-2404.

Laurent TC and Hascall VC (1997) Hyaluronan: structure and physical properties. Glycoforum (at: http://www.glycoforum.gr.jp/science/hyaluronan/ HA01/HA01E.html).

Lee R and Droller MJ (2000) The natural history of bladder cancer. Implications for therapy. Urol Clin North Am., 27, 1-13.

Lepperdinger G, Strobl B and Kreil G (1998) Hyal2, a human gene expressed in many cells, encodes a lysosomal hyaluronidase with a novel type of specificity. J. Bio. Chem., 273, 22466-22470.

Lerman MI and Minna JD (2000) The 630-kb lung cancer homologous deletion region on human chromosome 3p21.3: identification and evaluation of the resident candidate tumor suppressor genes. The International Lung Cancer Chromosome 3p21.3 Tumor Suppressor Gene Consortium. Cancer Res., 60, 6116-6133.

Liu SL, Duh FM, Lerman MI and Miller AD (2003) Role of virus receptor Hyal2 in oncogenic transformation of rodent fibroblasts by sheep betaretrovirus env proteins. $\mathrm{J}$ Virol., 7, 2850-2858. 
Lokeshwar VB, Rubinowiz D, Achroeder GL, Forgacs E, Minna JD, Block NL, Nadji M and Lokeshwar BL (2001) Stroma and epithelial expression of tumor markers hyaluronic acid and HYAL1 hyaluronidase in protate cancer. J. Bio. Chem., 276, 11922-11932.

Lokeshwar VB, Schroder GL, Carey RI, Soloway MS and Lida N (2002) Regulation of hyaluronidase activitiy by alternative mRNA splicing. J. Bio. Chem., 277, 3365433663.

McBride WH and Bard JBL (1979) Hyaluronidase-sensitive halos around adherent cells. J. Exp. Med., 149, 507-515.

Natowicz MR and Triggs-Raine B (2001) Mucopolysaccharidosis IX: An update on this hyaluronidase deficiency disorder and the complexity of the organization of the hyaluronidase genes. Strategies for therapy of MPS and related diseases and 16th Annual MPS Conference, June 21-24, 2001 UCLA Sunset Village. (at: http://www.arc.ucla.edu/biolchem/mps/01 therapy/01program.htm\#sessions).

Naz KR and Vanek MC (1998) Testis-specific proteins and their role in contraceptive vaccine. Bioscience, 3, e39-e48.

Nef S and Parada LF (1999) Cryptorchidism in mice mutant for Insl3. Nat Genet., 22, 295299.

Novak U, Stylli SS, Kaye HA and Lepperdinger G (1999) Hyaluronidase-2 overexpression accelerates intracerebral but not subcutaneous tumor formation of murine astrocytoma cells. Cancer Research, 59, 6246-6250.

Okulewicz A, Lonc E and Borgsteede FH (2002) Ascaris nematodes in domestic and wild terrestail mammals. Pol. J. Vet Sci., 5, 277-281.

Olsen A, Permin A and Roepstoff A (2001) Chicken and pigs as transport hosts for Ascaris, Trichuris and Oesophagostomum eggs. Parasitology, 123, 325-330.

Palmarini M and Fan H (2001) Retrovirus-induced ovine pulmonary adenocarcinoma, an animal model for lung cancer. J Natl Cancer Inst., 93, 1603-1614.

Rai SK, Duh FM, Vigdorovich V, Danilkovitch-Miagkova A, Lerman MI, Miller AD (2001) Candidate tumor suppressor HYAL2 is a glycosylphosphatidylinositol (GPI)anchored cell-surface receptor for jaagsiekte sheep retrovirus, the envelope protein which mediates oncogenic transformation. Proc. Natl. Acad. Sci., 98, 4443-4448.

Rhoads ML, Fetterer RH and Urban Jr JF (2001) Release of hyaluronidase during in vitro development of Ascaris suum from the third to fourth larval stage. Paraitol Res., 87, 693-697.

Rothschild MF, Christian LL and Blanchard W (1988) Evidence for multigene control of cryptorchidism in swine. J. Hered., 79, 313-314.

Rothschild MF and Ruvinsky A (1998) Genetics of abnormalities. Technical survice update. (at: http://www.genexswinegroup.ca/pdfs/TUapr99.pdf). 
Salustri A and Fulop C (1998) Role of hyaluronan during ovulation and fertilization. Glycoforum. (at: http://www.glycoforum.gr.jp/science/hyaluronan/HA03/HA03E.html)

Seravac (2001) Category: Pharmaceutical Enzymes \& Proteins Product: Hyaluronidase (at: http://www.seravac.co.za/products/browse/?prodID=22)

Shuttleworth TL, Wilson MD, Wicklow BA, Wilkins JA and Triggs-Raine BL (2002) Characterization of the Murine Hyaluronidase Gene Region Reveals Complex Organization and Cotranscription of Hyal1 with Downstream Genes, Fus2 and Hyal3. J. Biol. Chem., 277, 23008-23018.

Simionescu DT, Lovekamp JJ and Vyavahare NR (2003) Glycosamino glycan-degrading enzymes in porcine aortic heart valves: implications for bioprosthetic heart valve degeneration. J Heart Valve Dis., 12, 217-225.

Stern R (1995) The Breast Tumor Suppressor Function of Hyaluronidase. Tumor biology. California Breast cancer research program. Research project awards (at: http://www.cbcrp.org/publications/compendia/1995/page_10.php).

Stern R and Csoka BA (2000) Mammalian hyaluronidase. Glycoforum (at: http://www.glycoforum.gr.jp/science/hyaluronan/HA15/HA15E.html).

Swain JE and Krisher RL (2002) Changes in Pyruvate and Glucose Metabolism by Developing Porcine Embryos Produced In Vitro. Swine Research Report, Department of Animal Sciences, Purdue University (at: http://www.ansc.purdue.edu/swine/ swineday/sday02/20.html).

Takahashi I, Takahashi T, Komatsu M, Matsuda J, Takada G (2001) Ala/Thr60 variant of the Leydig insulin-like hormone is not associated with cryptorchidism in the Japanese population. Pediatr. Int., 43: 256-258.

Todd See M (2003) Genetic Abnormalities. Make Available Relevant Research-based homepage, Department of Animal Science, North Carolina State. University (at: http://mark.asci.ncsu.edu/Genetics/selection/abnormal.html).

Tomboc M, Lee PA, Mitwally MF, Schneck FX, Bellinger M and Selma SF (2000) Insulin-like 3/Relexin-like factor gene mutations are associated with cryptochidism. J. Clin Endo Met., 85, 4013-4018.

Toole BP (2001) Hyaluronan in morphogenesis. Semin Cell Dev Biol., 12, 79-87.

Toole BP, Biswas C and Gross J (1979) Hyaluronate and invasiveness of the rabbit V2 carcinoma. Proc. Natl. Acad. Sci., 76, 6299-6303.

Toole BP, Wight NT and Tammi ML (2002) Hyaluronan-Cell Interactions in Cancer and Vascular Disease. J. Biol. Chem., 277, 4593-4596.

Triggs-Raine B, Salo TJ, Zhang H, Wicklow BA and Natowicz MR (1999) Mutations in HYAL1, a member of a tandemly distributed multigene family encoding disparate hyaluronidase activities, cause a newly described lysosomal disorder, mucopolysaccharidosis IX. Genetics, 96, 6296-6300. 
Turley EA, Noble PW and Bourguignon LYW (2002) Signaling properties of hyaluronan receptors. J. Biol. Chem., 277, 4589-4592.

Urban Jr JF, Rasmussen T, Ishiwata K, Cheever A, Pilitt P, Eriksen L, Nansen P and Murrell K (1998) Migration and development of Ascaris suum larvae in erthrocebus patas: model for visceral larva migrans in humans. TEKTRAN, United States Department of Agriculture: Agriculture Reseach Service.

White JM (1992) Membrane fusion. Science, 258, 917-922.

Wei M, Farida L, Scott B, Kashuba V, Chen J, Duh F, Sekido Y, Lee C, Geil L, Kuzmin I, Zabarovky E, Klein G, Zbar B, Minna JD and Lerman IM (1996) Construction of a 600-kilobase cosmid clone contig and generation of a transcriptional map surrounding the lung cancer tumor suppressor gene (TSG) locus on human chromosome 3p21.3: progress toward the isolation of a lung cancer TSG. Cancer Research, 56, 1487-1492.

Wensing CJ (1988) The embryology of testiscular descent. Horm. Res., 30, 144-152.

Wolfe JE (2002) Genetic concerns. Rose Croft Terrier Web (at: http://members.tripod.com / Jerrier/Genetics.html).

Woodley LC (2002) Initiation of protein synthesis. University of Mississippi Medical Center Department of Biochemistry. (at: http://biochemistry.umc.edu/woodley.html).

Zegerman P, Bannister AJ, Kouzarides T (2000) The putative tumour suppressor Fus-2 is an N-acetyltransferase. Oncogene, 19,161-163.

Zetter Research Lab (2003) Research projects; Tumor metastasis. Children' hospital Boston, United Kingdom (at: http://www.zetterlab.org/research/tumor_metastasis.html).

Zhang L, Underhill CB and Chen L (1995) Hyaluronan on the surface of tumor cells is correlated with metastatic behavior. Cancer Res., 55, 428-433.

Zhu L, Hope TJ, Hall J, Davies A, Stern M, Muller-Eberhard U, Stern R and Parslow TG (1994) Molecular cloning of a mammalian hyaluronidase reveals identity with hemopexin, a serum heme-binding protein. J. Biol. Chem., 269, 32092-32097.

Zimmermann S, Steding G, Emmen JM, Brinkmann AO, Nayernia K, Holstein AF, Engel $\mathrm{W}$ and Adham IM (1999) Targeted disruption of the Insl3 gene causes bilateral cryptorchidism. Mol. Endocrinol., 13: 681-691. 


\section{ACKNOWLEDGEMENTS}

I would like to express appreciation and gratitude to my supervisor, Prof. Dr. Dr. Bertram Brenig for his invaluable guidance and support of the graduate study. I wish to express my thanks to my advisor, Dr. Christoph Knorr, for many fruitful discussions and for always having time to help and advise.

Acknowledgement is also expressed to Assoc. Prof. Dr. Therdchai Verasilp, for constructive suggestions, to Prof. Dr. Udo ter Meulen and Prof. Dr. Gabriele HoerstgenSchwark for support and the cooperation between Chiangmai University and the University of Goettingen. In particular, I am indebted to all members of the lab, especially to Mr. Kefei Chen. I thank, Mrs. Alexandra Siebels and Miss Viola Raupach, for their technical assistances, help and suggestions through this research. Special thanks are given to Dr. Nattaphon Chongkasitkit and Miss Ratchaneewan Wongprachan for statistical analyzes.

Finally, high pleasure is due to my family for all their love, encouragement, and support throughout the study period. 


\section{CURRICULUM VITAE}

PERSONAL INFORMATION

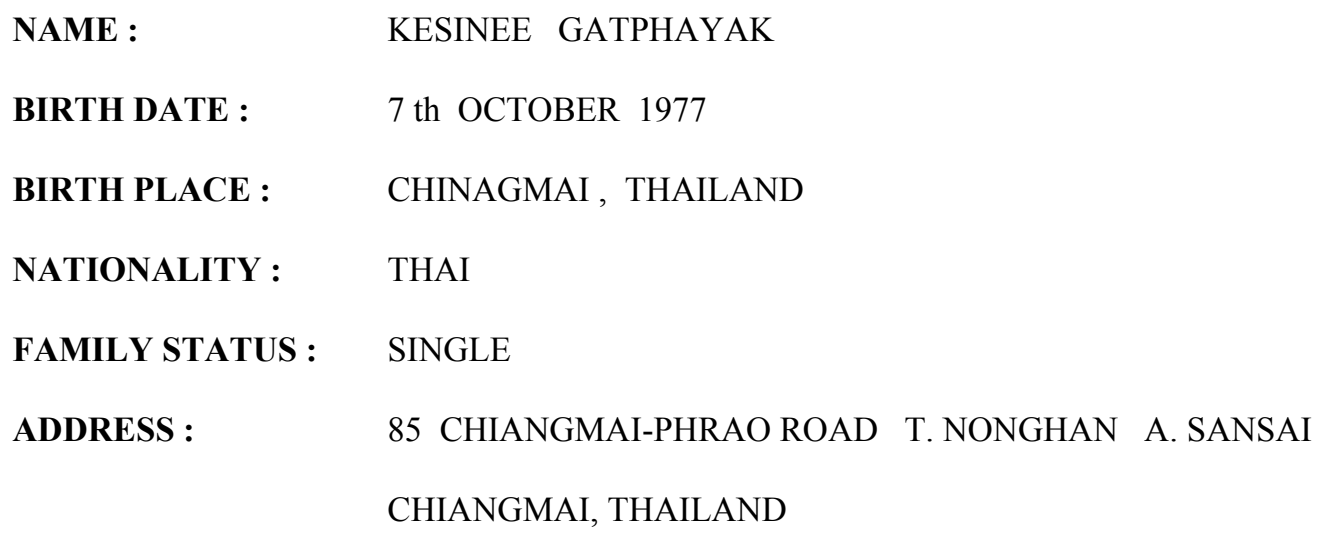

\section{WORK EXPERINCE :}

OCTOBER 1997

APRIL 1998

MAY 1998

APRIL-MAY 1999
JOB TRAINING AT HIGHLAND AGRICULTURE, CHIANGMAI, THAILAND JOB TRAINING AT POULTRY FRAMING, C.P GROUP, THAILAND JOB TRAINING IN FEED INDUSTRY, C.P GROUP, THAILAND AN EXCHANGE STUDENT OF THE BRITISH FARMER GROUP FOR INTERNATIONAL DEVELOPMENT IN HEREFORDSHIRE, UNITED KINGDOM 
MAY-NOVEMBER 2000

RESEARCH WORK FOR MASTER THESIS AT THE INSTITUTE OF ANIMAL BREEDING SCIENCE, RHEINISCHE FRIEDRICH-WILHELMS UNIVERSITY BONN, GERMANY

NOVEMBER 2001-FEBUARY 2004

Ph.D RESEARCH AT INSTITUTE OF VETERINARY MEDICINE, GEORGAUGUST-UNIVERSITÄT GÖTTINGEN, GERMANY 